\title{
Applying linguistics to explore adult-child communication within child psychotherapy: Designing an approach to inform research and practice
}

Jean Lillian Paul ${ }^{1,2}$, Hanna Christiansen ${ }^{3}$, Melinda Goodyear ${ }^{4}$, Lesley Stirling ${ }^{5}$

1. Mental Health Research Program, The Village, Ludwig Boltzmann Gesellschaft, Innsbruck, Austria, 2. Medical University Innsbruck, Department of Psychiatry, Psychotherapy and Psychosomatics, Division of Psychiatry I, Innsbruck, Austria, 3. Philipps University Marburg, Department of Clinical Child and Adolescent Psychology, Marburg, Germany, 4. School of Rural Health, Monash University, Melbourne, Australia, 5. The School of Languages and Linguistics, The University of Melbourne, Melbourne, Australia

Objectives: Conversation Analysis of video-recordings will produce practice recommendations for interacting with children whose parents have a mental illness (COPMI).

Aims: Understand the nature and possibilities of children's participation in conversations about their concerns when their parent has a mental illness. Inform development and training of practice approaches within the Austrian 'Village Project', How to raise a village to raise a child.

Background:

- Ethical imperative to support child participation (UN Convention on the Rights of the Child)

- Importance of 'assent', supporting children to develop own 'voice' in healthcare > acknowledged within child health research

- However, children of parents with mental illnesses may lack adult support in healthcare interactions

- Enhancing practitioner-child communication is important to ensure these children's needs are addressed

- Doctors communicate differently with children than with adults, using specific 'communicative frames'1

- Within paediatric encounters, most doctor talk is directed to parents rather than children ${ }^{2}$

- Limited research has shown that children retain some information better than their parents ${ }^{3}$

- Increased proportion of doctor-child communication compared to doctor-parent communication can increase parental satisfaction ${ }^{3}$

- Specific voice quality and intonation pattern, wider pitch range and higher pitch, slower pace, used by clinicians when addressing children $^{4,5}$

Materials and Methods: Conversation Analysis: micro-analysis of the sequentially unfolding interaction, on its own terms

- Interactive frames and footing 6

- "The superordinate message (or metamessage) about what activity is being engaged in when words are uttered in interaction... Participants identify frames by recognition of familiar linguistic and behavioural routines, as well as conventionalised use of linguistic and paralinguistic features - in other words, what you say and how you say it."7

\section{Village Research Project ${ }^{8}$ DOI 10.3389/fpsyt.2019.00233}

- 4 years, based in Tyrol, Austria, children at the centre with their voices and needs being specifically addressed

- Co-development, implementation and evaluation of two practice approaches to improve:

(1) sensitive identification of COPMI through their parent, and

(2) strengthen formal and informal child-focused support

- Understanding and improving current practice
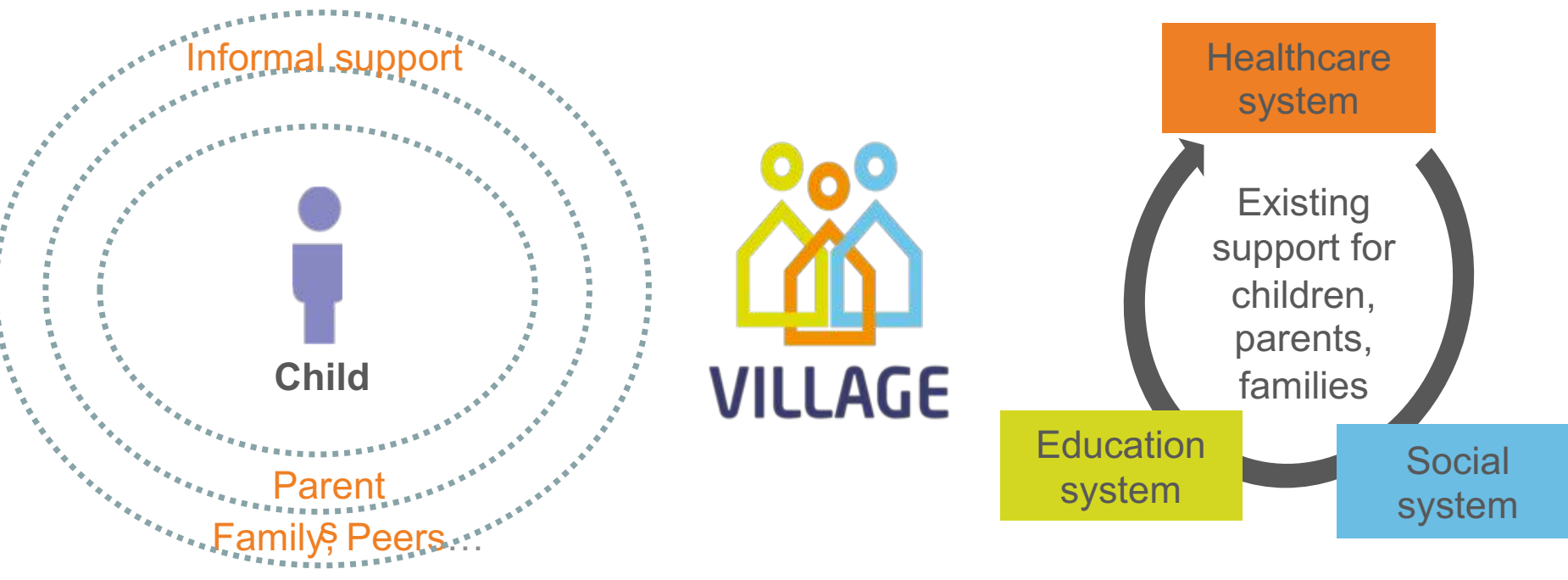

Results:

- Through close consultation with the clinical team, an approach was designed capitalising on investigators' expertise in linguistics, child development, psychopathology, and sociology.

- Involves a series of sociological and linguistic micro-analyses (Conversation Analysis) across approximately 30 consultations between therapists and children in Marburg, Germany.

- Consultations include therapists who are trained and those still in training and cover initial sessions and those in which therapists have developed a rapport with the child.

- Video-recordings are transcribed and translated into English, however German speakers are engaged in analysis to identify cultural nuances and support translations.

- Methodological approaches developed and findings identified during this project are informing training to support child participation within conversations with children about their social support needs.

Conclusion: Methodological approaches developed, and findings identified during this project, will inform the larger Village Project within the field of child mental health, importantly, addressing knowledge gaps in this area and driving practice change.

References: 1. Goffman E. (1982). Interaction ritual: Essays in face to face behavior. NY, 2. Tates K \& Meeuwesen L. (2001). Doctor-parent-child communication. A (re)view of the literature. Soc Sci Med, 52:839-51, 3. Pantell, R. H., Stewart, T. J., Dias, J. K., Wells, P. and Ross, A. W. (1982). Physician communication with children and parents. Pediatrics, 70(3), 396-402, 4., Galloway, C. \& Richards, B. (eds.) (1994). Input and interaction in language acquisition. CUP, 5. Snow, C. (1995). Issues in the study of input. The handbook of child language, ed. P. Fletcher \& B. MacWhinney, 180-93. Oxford: Blackwell, 6. Goffman, E. (1981). Forms of talk. Oxford: Blackwell, 7. Tannen D. \& Wallat C. (1983). Doctor/mother/child communication: linguistic analysis of a pediatric interaction. In A. D. Todd \& S. Fisher (Eds.), The social organization of doctor-patient communication (2nd ed., pp. 203-219). NJ: Ablex, p. 207, 8. Christiansen H, et al., (2019) Improving Identification and Child-Focused Collaborative Care for Children of Parents With a Mental Illness in Tyrol, Austria. Front. Psychiatry 10:233.

\section{Co-Investigator Organisations}

Stakeholder Organisations
$\Delta \mathbf{\nabla}$ 